This is an Accepted Manuscript of an article published by Taylor \& Francis Group in Journal of Social Welfare and Family Law on 03 Feb 2017, available online: http://www.tandfonline.com/10.1080/09649069.2016.1272781

Authors' un-proofed copy of paper submitted to Journal of Social Welfare and Family Law

Acceptance date - 19.09.2016, predicted publication in January 2017 Issue 39-1

\title{
Contested views of expertise in children's care and permanence proceedings
}

\section{Abstract}

In this article, we consider different perspectives on who is best able to provide relevant and helpful expertise in public law cases where the long-term care of children is under consideration. Opinions vary and sometimes conflict on the respective importance of legal, child development, and lay understandings. These opinions relate to views on rights, appropriate procedures, decision-making processes, and the effects of decisions on children.

Firstly, we summarise literature relevant to the knowledge and skills of three key groups of decisionmakers within the Scottish child care system: legal professionals, child care professionals and lay decision-makers, and outline literature about guardians ad litem and their counterparts. We then discuss issues of expertise emerging from a study exploring the reasons for, and impact of, the appointment of safeguarders (who, in Scotland, perform a similar role to guardians).

We conclude that there may be an increasing tendency for disagreement and a lack of clarity about who has the most relevant and helpful expertise to hearings; this may have negative effects for children.

\section{Keywords}

Permanence; guardians; experts; safeguarders; Children's Hearings; legal representation; safeguarding; best interests 


\section{Introduction}

This article is concerned with different perspectives on what constitutes relevant and helpful expertise in public law cases where the care of children is under consideration. We draw on international literature and a study carried out in Scotland to illuminate the issues and dilemmas involved. The recognition of professional expertise in both law and child care professions is typically based on lengthy education and workplace induction of the trainee, or neophyte professional alongside suitable peers (Eraut, 1998). This aims to impart three main elements in relation to a specialist area: knowledge and understanding, relevant skills, and a commitment to agreed ethics or values. We shall see that each of these can be an important consideration in judgements about what expertise is appropriate in child care and protection cases.

In most countries, when the state is considering compulsory intervention in children's lives, it is accepted that legal expertise should play the predominant role in the presentation of evidence for decision-making. Furthermore, the key decision-makers are often legally qualified judges, or magistrates guided by legally qualified officers (Russell, 2012).

However, as with many areas of the law, other professionals have an important part to play; for example, they often provide verbal and/or written reports, or act as expert witnesses (Prescott, 2013; Ward, 2012). Equally, lay involvement in decision-making is a tradition in many countries. Lay people are by definition non-experts, though they often receive training relevant to their roles, and bring with them a variety of other valuable skills. Citizen juries provide a well-known example, but in relation to children, other roles are important, notably lay magistrates and guardians (or guardians ad litem).

Recurrent debates have ensued about the types of expertise required to ensure that judicial processes reach appropriate decisions (e.g. Duquette \& Darwall, 2012; Mooney \& Lockyer, 2012). Alongside considerations of human rights and due process, these debates have also been about the quality, speed, and cost of decision-making.

In Scotland, cases concerning children's welfare, safety and behaviour are usually heard within a noncourt system, Children's Hearings. This system is unusual as legal professionals have only a minor role in the presentation of information and decision-making. With certain exceptions noted below, lay people make decisions. They take into account information provided by social work, legal and other professionals, as well as family members. However, findings from our study suggest that decisionmakers value different kinds of expertise to a greater or lesser extent. We argue that this can have 
negative consequences for children.

\section{Scotland's Children's Hearings System}

In most jurisdictions, children's public law decisions are made by judges or their equivalents in children's, family or youth courts, sometimes assisted by lay people. In some countries, notably in northern Europe, there is a tradition of local government politicians and officials being involved in legally enforceable decisions, and this used to happen with respect to the assumption of parents' rights by local authorities in the UK.

Scotland is unusual in that most cases are dealt with at Children's Hearings where decisions are made by a panel of three lay people (Lockyer \& Stone, 1998; Norrie, 2013). They have the power to make compulsory supervision orders, which may specify that a child live away from the family home.

Children's Hearings deal with both children who offend and children whose welfare or safety is a cause for concern. Thus, they handle in the same way and in the same place cases that separate family and youth courts would handle in other parts of the UK, or which in the US would be treated differently as delinquency or dependency cases.

Hearings take place in relatively informal settings, usually with panel members, family members, and professionals seated round the same table. Since their inception in 1971, Children's Hearings have been imbued with a particular ethos. This is grounded in the Kilbrandon Report (1964), which recommended the introduction of the hearings system and continues to be often cited as a guide for participants in hearings (Hill \& Taylor, 2012). For instance, hearings are meant to treat the child as part of a family and community, although the child's individual rights are recognised, and the child's best interests and welfare should be the paramount consideration. In addition, wherever possible hearings should make decisions in a consensual fashion, with the agreement of children and parents. This aspect has come under strain at times due to the rise in the proportion of care and protection referrals, which are often highly contested, relative to those prompted by offences (SCRA, 2015).

Initially, legal representation in hearings was very rare, it being assumed that the child her/himself, parents, social workers, and others would convey the views of the child effectively (Lockyer \& Stone, 1998). However, partly under the influence of the UN Convention on the Rights of the Child and the European Convention on Human Rights, legal representation of both children and parents has become more common; even so, it is still the exception (Norrie, 2013).

An independent official, the Children's Reporter, makes referrals to hearings based on notifications by 
the police, social workers, and others. Many reporters are trained lawyers, but some come from other professional backgrounds including social care.

Local authorities are legally required to provide a report on the child to the hearings (Children's Hearings (Scotland) Act 2011, s. 60). Reports are prepared and presented to hearings by social workers, but in accordance with the Getting it Right for Every Child ${ }^{1}$ principles, these often integrate information from other professionals or multi-disciplinary assessments. Social workers attend the hearings, since the authority is required to implement hearings' decisions and provide analysis, assessments and information that are valued by panel members (Norrie, 2013; Taylor, Hill, \& Milligan, 2015). Education reports are normally submitted for children of school age, and reports from other professionals may be requested (e.g. from health visitors, parents'support workers, and so on).

A hearing may also decide to appoint a safeguarder in a role similar to that performed by guardians elsewhere, i.e. to act in the child's best interest and provide the hearing with an assessment of the child's situation and needs (Hill, Lockyer, Morton, Batchelor, \& Scott, 2003 discussed below).

It is important to recognise that courts and Sheriffs (Scottish judges) have an important part to play in a minority of cases. Following Kilbrandon recommendations, Children's Hearings do not deal with the facts of the case, but have the responsibility for making the disposal (what elsewhere might be termed a sentence). Usually the facts are accepted by parents and children, but when they dispute the grounds (reasons) for referral to a hearing, Sheriffs are asked to adjudicate. Similarly, if a parent or child disagrees with the decision of a hearing, they can lodge an appeal to a Sheriff (Children's Hearings (Scotland) Act 2011, s. 154). Sheriffs also deal with applications for emergency protection orders and for adoption or permanence orders.

\section{Outline of the present study}

Although previous research had shown that overall safeguarders were well regarded by panel members and families (Hill et al., 2003), recently concern has been expressed that in some instances appointment of a safeguarder may result in unnecessary delays with negative effects for the child. Hence, a study was undertaken to examine the reasons for safeguarders' appointment and their perceived impact on decision-making processes from the points of view of panel members, social workers and safeguarders

\footnotetext{
${ }^{1}$ Getting it Right for Every Child (GIRFEC) is a policy initiative in Scotland concerned with promoting children's wellbeing through integrated service delivery: see www.gov.scot/Topics/People/Young-People/gettingitright
} 
themselves (Gadda, Hill, Young, \& Welch, 2015).

The methods used were online questionnaires with open and pre-categorised questions, focus group discussions, and individual interviews. In all, more than 200 people filled in questionnaires (122 panel members, 62 safeguarders and 45 social workers). Survey respondents were also asked to indicate whether they would be willing to take part in further elements of the study, and from these responses, sixty-nine individuals were involved in group discussions or interviews (20 panel members, 19 safeguarders, and 30 social workers). The study recruited panel members and safeguarders through their respective national organisations, Children's Hearings Scotland and the National Safeguarder Panel. It was not logistically possible to include all local authority social workers. Instead, we asked a convenience sample of six of the 32 Scottish local authorities whether they were interested in taking part in the research and circulating invitations to relevant social workers. Four authorities agreed, and we promised them anonymity. The University of Strathclyde Ethics Committee gave approval for the study, and fieldwork took place between October 2013 and November 2014.

For the online questionnaires, we used Qualtrics, an online survey tool used for building and distributing questionnaires, as well as collecting responses. We carried out analysis of numeric data from the questionnaire using the statistical tools available within Qualtrics. These allowed us to run frequency tables, produce basic summary statistics, and compare results from different groups. Where there were apparent differences, we did not test for statistical significance as we felt the numbers of participants too low to provide a reliable indication. Instead, we looked to the qualitative analyses to help confirm and explain any apparent differences. Textual data, both from questionnaires and individual and group discussions, were input into NVivo10 and analysed qualitatively for themes (Braun \& Clarke, 2006).

Despite our best efforts to reach all safeguarders and panel members in Scotland, only a proportion of each group took part in the study (approximately $45 \%$ and $6 \%$ respectively). The participation rate of panel members may be relatively low due to them being volunteers with limited available time, or because some may prefer other means of communication. The relatively high rate of participation for safeguarders might have been higher still, but at the time of the research, the National Safeguarder Panel was relatively new, and electronic systems of communication with members were being finetuned. Similarly, around $41 \%$ of invited social workers from the four participating local authorities took part in the study.

Our response rates do not allow us to claim that our findings are representative of Scotland, and further research should explore in more detail some of the issues raised here. A further limitation of the study is that our resources and remit did not allow for obtaining the views of children, parents, carers or 
children's reporters; this would be desirable in future.

Before discussing how our findings highlighted different perceptions about the skills, knowledge and values most relevant to good and timely decision-making, we present a short review of literature on these matters from different jurisdictions.

\section{Relevant expertise: overview of the literature}

We briefly review literature relevant to different types of expertise deployed in decision-making about the care of children. In doing so, we focus on how the knowledge and skills of three groups underpins their claims to expertise: legal representatives, child care professionals, and lay people. We conclude our review by briefly examining information about the knowledge, skill, and backgrounds of guardians or safeguarders, who may fit any of these three categories, depending on the jurisdiction.

\section{The expertise of legal representatives}

It is a central tenet of nearly all legal systems and international human rights that individuals involved in legal proceedings, including children, are entitled to representation by qualified law practitioners (solicitors, attorneys, etc.) (Lehrmann, 2010; Ryrstedt \& Masttson, 2008). Lawyers are assumed to have not only knowledge of, and ready access to relevant statutes, case law and so on, but to also have skills in presenting arguments and an ethic of commitment to their clients' wishes. In England, it is recognised that lawyers should act on their client's instructions, but equally, they have duties to the court and must not make unfounded claims (Masson, 2012). Law is regarded as an archetypal profession and lawyers typically undergo a lengthy period of training that includes academic learning and practice-based training (Abbott \& Wallace, 1990). In order to qualify, they must master a large corpus of knowledge and acquire an appropriate set of professional mores (Abbott \& Wallace, 1990).

In the US, it is normal for a child to have legal representation in care and criminal proceedings (Duquette \& Darwall, 2012; Lehrmann, 2010). In Sweden, all children under 15 in family proceedings have a legal representative, whose role is to act in the child's best interests and ensure the child's procedural and substantive rights are upheld (Ryrstedt \& Mattsson, 2008). In certain Australian states all children must be legally represented in care and protection proceedings, though in others exceptions are made e.g. because a child is too young to provide instructions (Victoria) or has made an informed decision not to be represented (South Australia) (ALRC, 1998).

Among the arguments presented in favour of legal representation is children's need for help in 
understanding legal procedures and options and for assistance where necessary to challenge the state's powers to remove a child from home, potentially indefinitely (Duquette \& Darwall, 2012). Bilson and White (2005) argue that legal advocacy is necessary to prevent children's participatory rights being overridden as their 'best interests are determined by powerful adults' (p. 236). A countervailing view that appears in a minority of sources is that lawyers may be unhelpful as they may substitute their own views about what is best for the child, when they are not qualified to do so, or may see the child in isolation from the family and community context (Duquette \& Darwall, 2012; Mooney \& Lockyer, 2012).

The question then arises of when legal representatives should stoutly pursue the child's expressed wishes, and when they should pursue what is in the child's interest, where the two do not coincide. Only a few jurisdictions give guidance to lawyers about how they should decide when to switch from advocating a child's views to representing their best interests (Lehrmann, 2010). This situation has persisted for some time: Duquette (1994) acknowledged that 'attorneys in the United States are quite muddled about this issue' (p. 137). He stated that many advocated for the child's best interests as they saw it. In Canberra, legal representatives are obliged to inform the Court whether they are acting under instruction, in the young person or child's best interests, or both (Thomson, McArthur, \& Camilleri, 2015).

One possible response to the interest-wishes dilemma is a dual approach. Duquette (2007)proposed that representatives should follow a 'best interests' principle for children who they see as too young to communicate or make rational decisions, but for older children they ought to become advocates for the child's views. Mooney and Lockyer (2012) observe that in America lawyers usually act as 'zealous advocates', but may switch to best interests when they are convinced that what a child wants is contrary to their welfare needs. As noted above, decisions about in what circumstances to adopt which role may result from arbitrary judgements; lawyers do not normally receive training for this (Lehrmann, 2010).

Moreover, it is not clear how legal training prepares a lawyer to determine what is in a child's interests. As Mooney and Lockyer (2012) indicate, few lawyers in the US and UK are trained in child development, child psychology or how to communicate with children. An Australian study similarly found that many Children's Court stakeholders expressed concern that lawyers' knowledge and skills in relation to children is inadequate (Thomson et al., 2015).

During the early years of the Scottish Children's Hearings, legal representatives were notable by their absence. They were not precluded, but no provision existed to assist with the cost. Children who were old enough to do so (and parents) were expected to voice their own views, while panel members and 
social workers were under a legal duty to take account of children's wishes. Lockyer (1994) pointed out that the rules, which still apply, allow any person to attend a hearing to represent a child, but significantly, the role of the representative was to assist the child in the discussion of the case and not to act as an agent for the child. Lockyer also noted that within the non-adversarial model of hearings, it was not appropriate for representatives to take sides.

The frequency with which lawyers are involved in Children's Hearings has changed over time. As a result of a legal challenge, the Scottish Court of Session ruled in the 1990s that the lack of paid legal representation at hearings was in breach of the European Convention on Human Rights (article 6) (Norrie, 2013). Interim arrangements to address this issue were superseded by the Children's Hearings (Scotland) Act 2011 (Kearney, 2000). This statute gave children and their parents or carers access to legal aid funds ${ }^{2}$ to pay for a solicitor in many circumstances. It also required the Scottish Legal Aid Board $^{3}$ (SLAB) to seek to ensure that funded legal representatives at hearings have 'an appropriate level of knowledge and expertise in relation to children and the Children's Hearings System' (Norrie, 2013, p. 8). SLAB has produced a Code of Practice ${ }^{4}$ that amongst other things, establishes that in order to be able to register and be eligible for this funding, solicitors and firms must not only have an understanding of the legislation governing the Children's Hearing System, but also an understanding of its ethos.

\section{The expertise of child care professionals}

Usually social workers or their equivalents provide information about children's development and needs. From its inception in the 19th Century, the profession of social work has occupied an 'uncomfortable place' between the public and private spheres. Social workers must balance competing allegiances, typically, to vulnerable individuals, and to the state (Parton, 1996). In one sense, social workers are independent professionals; their training requires mastery of a significant body of knowledge about child development, legislation, and family processes as well as social work values and complex

\footnotetext{
${ }^{2}$ In the UK individuals on low or modest income can request legal aid to help them towards the costs of legal advice and representation. Since June 2013 children and their parents/carers attending a hearing can apply to the Scottish Legal Aid Board for the Children's Legal Assistance. The money for legal aid comes from public funds.
}

\footnotetext{
${ }^{3}$ The Scottish Legal Aid Board manages the aid system in Scotland.
}

\footnotetext{
${ }^{4}$ The Scottish Legal Aid Board Code of Practice in relation to Children's Legal Assistance Cases is available from www.slab.org.uk/export/sites/default/common/documents/profession/practitioner_info_guides/Children
} sRegisterandDuty/Code_of_Practice_in_relation_to_Childrenxs_Legal_Assistance_February_2013.pdf 
communication skills. However, most are employed by local or regional government organisations and must simultaneously provide support to families and enact the will of the state; in doing so, they must work within prevailing policy, frameworks, and structures (Dickens, 2010; Gilbert \& Power, 2010; Kirton, 2009; Parton, 1996). For example, in Scotland local authority social workers now deliver their work within the framework provided by Getting it Right for Every Child ${ }^{5}$ (GIRFEC). This suite of guidance describes legally enforceable responsibilities on local authorities and social workers; for example, the responsibility in certain circumstances to prepare and deliver a multiagency Child's Plan.

In this regard, social work has similarities with a number of other occupations (e.g. teaching and nursing). These roles typically have less professional autonomy than classic professions (such as law and medicine); this somewhat ambiguous status being subject to organisational constraints, has resulted in the application of dual labels, such as 'semi-professionals' (Etzioni, 1969), 'bureau professionals' (Parry \& Parry, 1979), and more recently ‘situated professionals’ (Noordegraaf, 2007).

In the UK, US, Australia, and elsewhere it is usual for social work services and their equivalents to provide the main source of information on children and their families to courts or hearings. In the US, social workers will often give evidence to family courts in child protection cases, as well as in cases of contested child custody. Prescott (2013) argues that the task allocated to social workers by family courts is one of 'social investigation', and that due to their knowledge and skills, social workers are recognised as 'experts' who can 'assist judicial decision-making by providing predictive and diagnostic opinions of human thoughts and behaviour' to help determine the best interests of a child (p. 467).

In Australia, social workers have an important role in the Children's Courts that are responsible for handling both child protection cases and juvenile offending behaviour (Borowoski \& Sheehan, 2012). In England and Wales, social workers will provide information to family courts in care proceedings, as well as in cases of contested child custody. Under the 1989 Children Act local authorities' social work services can initiate care proceedings when there are adequate reasons to believe that a child is suffering or likely to suffer 'significant harm' (Beckett, McKeighe, \& Taylor, 2007). In cases where a child's custody is being contested, the court may request a 'welfare report' from the Children and Family Court Advisory Support Service (CAFCASS), in which case, social workers employed by CAFCASS will carry out the required social investigation and prepare a report to courts (Mantle, Williams, Leslie, Parsons, \& Shaffer, 2008).

\footnotetext{
${ }^{5}$ For more details of GIRFEC see www.gov.scot/Topics/People/Young-People/gettingitright
} 
In Scotland, local authority social workers have a key role in the Children's Hearings and are required to prepare clear recommendations based on a detailed analysis of information they have collected.

Panel members base their decisions on various professional reports, as well as on conversations with those present at the hearing (often including the child, his or her family and social worker). The reports social workers prepare for hearings are often the key source of information to panel members. Panel members' decisions are, more often than not, in agreement with social workers' recommendations (Hallett, Murray, Jamieson, \& Veitch, 1998; Henderson \& Hanson, 2012). Thus, although social workers are not responsible for making the decision, they have significant influence on it.

\section{The expertise of lay people}

By definition, lay people do not have related professional expertise. It is somewhat unusual for ordinary citizens to be given the primary role for legally enforceable decisions about children's welfare, or for such decisions to be made outside of a court setting. The advantages and disadvantages of lay people making recommendations or decisions in a legal context have been rehearsed in a number of places. Reid and Gillan (2007) argue that lay people have legitimate interest in the wellbeing of children in their community and hence may be entitled to play a part in public law decision-making about children. Lay people can tap into communal understandings of family lifestyles and acceptable levels of care; they can apply 'common sense' (Reid \& Gillan, 2007). Their 'expertise' thus derives not from a particular professional education but from lived experience (Liljegren, Höjer, \& Forkby, 2014). Lay participation also fulfils a public education role.

Lay people are usually unpaid volunteers and it has been suggested that this may save costs; however, when compared to professional decision-makers, they may seek more guidance from experts, which itself has time and cost implications.

Drawbacks of using lay people include the potential dangers of inappropriate moral (or moralistic) judgements, or a lack of skills required to make good decisions. In Finland, for example, lay boards were criticised for a lack of specialist knowledge, even though contradictory views existed on 'what kind of expertise counts and what qualifications decision-makers need' (Korpinen \& Poso, 2007, p. 46). Because of those criticisms, the law in Finland was changed in 2007, so that lay boards no longer made compulsory decisions, only recommendations to administrative courts.

There are different ways in which lay people may be recruited or selected. Reid and Gillan (2007) distinguish four ways in which lay people may be chosen to take part in decision-making: random 
selection, popular election, political appointment, or a mix of the above.

In Nordic countries, such as Denmark and Norway, it has been normal for many years for Boards of lay members to make or recommend compulsory orders for the protection and care of children. Rather than direct citizen participation (as in Scotland), the local community is represented indirectly by elected representatives based on considerations of party-political democracy. Board members are chosen from among already elected politicians rather than direct election to the Board, an example of Reid and Gillan's mixed category. Usually, these elected representatives are accompanied on the Boards by specialists like child psychologists (see for example Hetherington, Baistow, Katz, Mesie, \& Trowell, 2001).

Similarly in Sweden, 'working committees' make decisions about individual cases. These committees comprise delegates from local elected politicians mirroring the current political majority; delegates are 'expected to act as laypersons and disregard political ideology' in their decisions (Liljegren et al., 2014, p. 9). Their decisions need to be ratified by administrative courts, where a judge is also accompanied by three laypersons (Liljegren et al., 2014; Ryrstedt \& Masttson, 2008). Only in the rare cases of appeal, are decisions made by a court system with no lay people.

The UK as a whole has a tradition of lay justices of the peace and magistrates in juvenile and other courts. In England, Wales, and Northern Ireland, a panel of three includes a legally qualified judge and two lay people; this panel makes decisions in youth and family courts. A similar system operates in German youth courts.

In the past, appointment of lay magistrates tended to favour people from elite backgrounds (Reid \& Gillan, 2007), but in recent years there have been some efforts to counter this possibility. One example is legislation in Northern Ireland ${ }^{6}$, which introduced a new recruitment process intended to encourage appointment from a wide section of the community, as is the aim for Scottish panel members.

In Scotland, lay panel members hear cases relating to the care and protection of children, as well as cases concerning children's offending behaviour. The Scottish Children's Hearings work is rooted firmly in the Kilbrandon Report (1964). This suggested that facts, such as whether or not a child has committed an offence or been abused, are best determined by legally trained personnel following standard due process, but that decisions about children's upbringing do not require legal expertise.

\footnotetext{
${ }^{6}$ Lay Magistrates (Eligibility) (Northern Ireland) Order 2004
} 
Kilbrandon therefore recommended that, once the reasons for referral are admitted or proven, lay people should make decisions about what to do. The report envisaged that these would be individuals who 'either by knowledge or experience were considered to be specially qualified to consider children's problems' (Para 74). This suggests that they would be 'lay' as regards legal expertise but would have child-related professional or quasi-professional experience.

In practice, when hearings were introduced, a somewhat different conception of laity prevailed, following a model that privileged local community involvement rather than any special knowledge or experience. In this way, panel members were recruited from the local area and were expected to be broadly representative of the community. It was thought that ordinary members of the public would be well informed about appropriate child rearing in the relevant context. Moreover, it was hoped that the involvement of lay people would increase public awareness of children's problems and promote support for of the hearings system (Hill \& Taylor, 2012; Lockyer, 1992).

Panel members do indeed come from a wide range of occupational backgrounds, though professionals and middle-aged people are over represented (Lockyer, 1992). Nonetheless, Norrie (2009) commented that they are 'drawn from a much wider section of the community than any bench of judges' (p. 36) and so can be 'more readily trusted' to make decisions about childrearing. Anyone over the age of 18 who lives in the local area may volunteer to be considered to become a panel member. Members need no formal qualifications, but recruitment considers issues such as their ability to make sound decisions, empathise with young people, and communicate effectively. Panel members undergo training and relevant checks on their background.

\section{The expertise of safeguarders or guardians}

Many countries appoint guardians ad litem to advise courts and protect children's interests. Since 1974 all US states have been required by the Federal Government to have a guardian ad litem service (Duquette \& Darwall, 2012). This term ' guardian ad litem' is also current in some other jurisdictions like Northern Ireland, but in England and Wales the single word 'guardian' is preferred (not to be confused with guardians who have day-to-day legal responsibility for children). Although the precise remits of guardians and their equivalents vary, their primary or sole role is to promote the best interests of the children. The introduction of guardians in Germany was to help ensure the child is at the forefront of decision-making and does not become a mere 'object of the proceedings' (Stötzel \& Fegert, 2006).

In England and Wales, the first guardian panels were organised at local authority level, but in 2001, a new national non-departmental body was established, the Child and Family Courts Advisory and Support 
Service (CAFCASS) in England, with CAFCASS Cymru being responsible for Wales. The key responsibility of CAFCASS is to safeguard and promote the welfare of children in the courts. It does so by providing information, advice, and support to children and families, and by advising members of family courts. Although CAFCASS has been recently praised for its effective advocacy for children and young people and support to families (Ofsted, 2014), in some cases it has been criticised by judges as acting beyond its remit, and without effective judicial scrutiny (Doughty, 2009). There have been complaints that CAFCASS managers sometimes override the professional assessments of individual guardians, and that more generally, an ethos of managerialism has constrained the independence of guardians (Cover, 2012; Gupta \& Lloyd-Jones, 2010).

Scotland has for many years had curators ad litem who may be appointed to promote the interests of the child in court cases (e.g. adoption applications), but not in Children's Hearings. At the inception of the Children's Hearings in 1971, no equivalent role was created; however, in 1985, partly influenced by experience from elsewhere, safeguarders were introduced. For the last 30 years, both hearings and Sheriffs have been able to appoint a safeguarder. Until recently, individual local authorities managed panels of safeguarders, but in 2014 a national body was created to provide greater consistency and support. Unlike CAFCASS, the Scottish National Safeguarder Panel is managed by a voluntary organisation, Children 1st.

Initially safeguarders were to be used only when there was a conflict between parents and children. However, since the 1995 Act, appointments of a safeguarder must now be made in any case where the Children's Hearing, or the Sheriff consider it necessary in order to safeguard the welfare of the child in the proceedings (Children's Hearings (Scotland) Act 2011 Pt. 3). This reflects a contrast in emphasis with the situation in England and Wales, where a guardian must be appointed unless the court is satisfied this is not necessary (Children Act (1989) s41). In some US states guardians are appointed in every case (Duquette, 2001).

The professional backgrounds of guardians and safeguarders differ markedly from one country to another. Several countries, including Scotland, have no statutory requirements regarding qualifications and training, leading some to argue that the procedures for their appointment has been haphazard and opaque (Bilson \& White, 2005; Capita, 2004). In many states of the US, guardians were initially nonlawyer volunteers, though they often worked in a single agency alongside lawyers and perhaps social workers (Duquette, 1994). In response to various concerns about their training, successive Federal Child Abuse and Protection Acts have progressively tightened requirements. Now guardians ad litem in the US should receive appropriate role-specific training and be either an attorney or court-appointed special 
advocate (Duquette \& Darwall, 2012). Some states stipulate that a guardian must be an attorney, but others permit non-lawyer guardians (Glynn, 2007). For example, the Florida Guardian ad Litem Program states that 'anyone with common sense, compassion and dedication to children can apply' to be a guardian ${ }^{7}$.

Guardians working for CAFCASS or CAFCASS Cymru are normally social workers and Northern Irish guardians ad litem are senior social workers. In Scotland, there are no statutory requirements for the role, but, in practice, the majority are either lawyers or social workers (often in retirement) (Gadda et al., 2015; Hill et al., 2003). Others have had teaching or other child-related experience, but a few cite no related work experience (Gadda et al., 2015; Hill et al., 2003). In the rest of the UK, guardians usually appoint a legal representative with whom they operate in tandem; this does not happen in Scotland.

\section{Study findings}

The majority of participants in the present study regarded the contribution of safeguarders positively, with $95 \%$ of panel members, $94 \%$ of safeguarders, and $54 \%$ of social workers agreeing with the statement: 'Safeguarders are a valuable resource for hearings'. However, the three groups of participants did express contrasting views about how valuable the contributions of safeguarders were, and these views were often justified in terms of differences in the perceived expertise, knowledge and values of safeguarders, social workers and lay decision-makers.

\section{Expertise}

\section{Perspectives on the expertise of Safeguarders}

Most panel members indicated implicitly or explicitly that safeguarders should be appointed when considering difficult decisions , and especially complex cases:

\section{[Safeguarders should be appointed] In sensitive cases where permanence is planned and contact with relevant persons is being reduced due to lack of quality [or] effect on [the] child, where a view on the wider picture is necessary... (Panel member, questionnaire)}

Often panel members suggested that safeguarders had special skills that allowed them to identify, and

\footnotetext{
${ }^{7}$ Further information about the Florida Guardian ad Litem Program can be found at www.guardianadlitem.org
} 
present important additional information or perspectives which otherwise would not be available:
I think one of the things that I've found particularly beneficial is that sometimes a safeguarder turns up information that we're not aware of. Now, I can't comment on why the information is sometimes not there, but the safeguarder will actually challenge social work, quite hard, some of them, about the information, and that can put a completely different perspective on it, and it also allows us perhaps, to make a better decision for the children. (Panel member, group discussion)

Because the ones who are good, are good, and they will extract information [...] that is not in any social work report, that's not in any feedback from parents, [...] there's nobody else can get that information independently. (Panel member, group discussion)

In this way, panel members often portrayed safeguarders as experts with extensive knowledge and experience. They thought safeguarders' expertise combined with their objectivity and independence to make their contributions particularly valuable:

Safeguarders are independent of all other parties and their advice is impartial and based on a wealth of experience. (Panel member, questionnaire)

Although most social workers agreed that safeguarders are a valuable part of the Children's Hearings system, they were often less certain than panel members of safeguarders' expertise. Some pointed out that neither they, nor panel members, knew the background or qualifications of individual safeguarders:

I don't know what their background is. I don't know what their experience is. That should be stated right at the front, because then you know what their bias is. And their understanding. I mean, that's the first question you'd be asked in court, if you were talking to an assessment. (Social worker, group discussion)

This lack of clarity about safeguarders' professional background led social workers to question the appropriateness of safeguarders' recommendations to the hearings, particularly when these differed from their own conclusions.

Unsurprisingly, safeguarders themselves believed that their expertise provided something to the hearings which no other professional or lay participant could provide: 
specified by the Panel, and includes an overall assessment in his/her report, together with the views and opinions of all the parties involved in the case on a personal and professional level. No other report is as all-encompassing in its scope, drawing together all the threads of the case and ending with clearly identified options and recommendations for action. (Safeguarder, questionnaire)

Legislation and guidance governing the role of safeguarders does not specify requirements for the role, other than the possession of 'appropriate experience' (Children 1st, 2014). It is currently not clear what 'appropriate experience' consists of, although Practice Standards and a Performance Monitoring Framework have been introduced recently. Good understanding of the Children's Hearing System is important, and this was demonstrated in safeguarders' survey responses, with about $90 \%$ declaring considerable or extensive prior experience of the hearings system.

The need for safeguarders to have previous knowledge and understanding of Children's Hearings has led to a situation where most safeguarders have either a legal or social work background. Just over half $(55 \%)$ of safeguarders taking part in the survey were lawyers (often with experience of family and child law) or social workers.

It was clear that most social workers and some panel members had reservations about safeguarders who were from a legal background:

I love safeguarders, but have a real issue with having solicitors as safeguarders.

(Social worker, interview)

These participants argued that solicitors typically had little or no understanding of child development and issues such as attachment and had minimal contact with the family:

...my biggest concern is that we don't even know what the qualification is for this person to provide that report. We don't know if they've got any understanding of child development, relationships, attachment, bonding, etc. (Social worker, questionnaire).

Safeguarders are often seen as experts, when they have limited childcare knowledge, and limited contact with family (Social worker, questionnaire)

Social workers were also concerned that, with some exceptions, safeguarders were not trained to communicate with children, and felt that as result, some safeguarders misinterpreted children's views. Similarly, some panel members also stated that certain legally trained safeguarders used language that was hard for children and families to understand, whilst other panel members also regarded such formal 
language as not 'in keeping' with the ethos of Children's Hearings:

I had a report in the other day from a safeguarder, about that length, and it was one where they'd been appointed and really they hadn't had enough time to look into it, but it was a really, you know, you'd have thought he was writing a report for the court. (Panel member, group discussion)

On the other hand, many more panel members were impressed by the written and oral presentation skills of legally trained safeguarders, as the following quote illustrates:

The legally trained [safeguarders are] very good at persuading an audience and making an argument, and [...] the person who's maybe a social work or other background, [...] are maybe just not as good at putting that point [...], reinforcing what they want to be heard.. (Panel member, focus group)

Legally qualified safeguarders often expressed the view that they were better qualified to perform the role than those safeguarders who were not lawyers, though some of their justifications were put forward more in relation to acting as a safeguarder in court rather than in hearings (e.g. when considering the facts or at an appeal):

There have been occasions when acting as a solicitor I have seen safeguarder reports where it was clear the safeguarder did not have an understanding of the statutory responsibilities of local authorities towards children and their families, or indeed the government guidance in terms of support responsibilities. (Safeguarder, questionnaire)

The majority of safeguarders who are not legally qualified are at best, ill-equipped to represent the interests of the safeguarded child in court. (Safeguarder, questionnaire)

As an English study also found (Masson, 2012), safeguarders suggested that Sheriffs, as lawyers themselves, appreciated the knowledge, skills, and values that legal training provided:

Sheriffs, generally speaking, like people they have known and trust; it's as simple as that. [...] There's a specific oath you need to take, which doesn't apply to nonlawyers, and obviously you're an officer of the court with all that involves. You've all sorts of professional obligations on top of your ordinary [safeguarders'] obligations, so Sheriffs like that. (Safeguarder, group discussion)

Many social workers believed that panel members' high regard for safeguarders was because legal 
training, which many of them had, was held in higher regard than social worker training:

It's as if, because the safeguarder would often be a solicitor, or usually be a solicitor, it would be as if their word had more weight than some social worker. I mean, there's still people who think we just walk in off the street and get a job in social work. (Social workers, group discussion)

Safeguarders without legal training were less sure about whether it was an advantage to the role, highlighting the importance of the knowledge and skills they could bring into a case:

We might not have a legal background but very often we bring different talents to [Children's Hearings]. I mean [name] and I are both teachers so we see children from a different point of view, working with them daily. You know, [name's] social work, so we're bringing, we're coming from a different side, which sometimes gives them a fresh outlook on things. (Safeguarder, group discussion)

Many panel members were also of the view that safeguarders in general were better than social workers at obtaining the views of children, young people, and their families:

But there's something just sometimes with the safeguarder that's a lot more natural and things come out that maybe wouldn't [...] the safeguarder does seem to tap into something that the child often feels they don't want to disclose. (Panel member, group discussion)

I think families have often welcomed the input of a safeguarder because they do feel that someone is listening to them. [...] the social worker can have put in all sorts of services, can have visited throughout quite a period of time, but it's just when the safeguarder goes and then spends an hour with the child, and an hour with this person, you know, the actual time may well be less, but the perception is they've had the ear of someone for a sort of period of time, and it has to be partly down to the very, very highly skilled listening skills that safeguarders have. (Panel member, group discussion)

A number of safeguarders gave detailed accounts of techniques they used to help put children at ease and express themselves openly, though a few admitted they lacked specialist skills in communicating with children.

\section{Perspectives on the expertise of local authority social workers}


Many panel members and safeguarders recognised and commended social workers' expertise:

I mean, social workers are very highly trained and skilled in the area of contact and they do make their recommendations based on, you know, evidence they have, but there can still be situations where, one's not doubting the social worker, not doubting the assessments, but there's enough doubt in your mind about whether this is the right decision, given all sorts of other information you've got. (Panel member, group discussion)

However, some panel members recognised that local authority social workers (as bureau-professionals) were not always able to use their full expertise due to organisational issues:

I mean, social workers today, for example, the amount of face-to-face contact they've got with the family is minimal, and a lot of children will hardly know who their social worker is, to be honest. (Safeguarder, group discussion)

Social workers often contrasted their professional expertise with that of safeguarders and, rightly or wrongly, tended to regard the panel's appointment of a safeguarder as indicating a lack of confidence in social work expertise:

If a safeguarder is appointed it is usually because panel members do not feel they can make a decision based on what the social worker has said or written. (Social worker, questionnaire)

Some social workers felt that their profession's knowledge and values were not understood or respected, by panel members:

In general social workers are not given the respect or understanding in regards to the social work profession as a whole, by children's panel members, who seem more concerned about parental rights to family life under the European Convention on Human Rights than the protection of children (Social worker, interview)

Panel members and safeguarders questioned the objectivity of social workers' assessments, suggesting that social worker reports were not purely based on professional judgement, but were influenced by the personal relationships that social workers establish with families, as well as by management requirements, and agency policies and resources:

... social work also come, don't they, with their own agenda? [...] they're balancing (limited) resources and needs, aren't they? (Panel member, group discussion) 
Safeguarders should be, everybody should be, providing a needs-led assessment but the reality is that's not what happens. Either because social work don't have the resources or the decision is actually not necessarily being made by the social worker [...]. The decision is being made by people who are at a meeting. And sometimes, I think, it's the person that shouts loudest. (Safeguarder, interview)

They contrasted this to the perceived independence of the safeguarder perspective:

... as an independent taking no sides, you're just purely looking at the evidence from the point of view of the welfare principle, at its truest form, you're the truest independent at that table, you're not social work with an agenda one side, you're not a solicitor with agenda the other side. You're looking purely from the point of view of this child. (Safeguarder, focus group).

Social workers disagreed. Although some recognised that, due to the nature of their work, they may become prejudiced towards some families, they saw their reports as being based at all times on the child's best interests, as assessed using their own professional knowledge and skills, as well as the views of other professionals:

Yes, families sometimes do not like the recommendations we are making. But panel members need to understand that this is not personal. It's a professional assessment, in the best interests of this child, as we see it. (Social worker, group discussion)

Social workers were aware that panel members and safeguarders sometimes saw them as biased, and many felt that panel members and safeguarders had an undeservedly poor view of social work knowledge and skills:
I was deeply shocked at a culture in Children's Hearings of an obvious lack of respect, by so many panel members for social workers, their work, [and] reports.
(Social worker, questionnaire)

Thus, social workers believed that panel members unnecessarily sought additional expertise to corroborate social work knowledge, which they felt was dismissed as being less reliable or credible than that of safeguarders:

I think there is a big issue with panel members, having a negative view of social workers and wanting to get, 'better', 'more credible' information from safeguarders and not respecting the professional nature of social work. (Social worker, 
questionnaire)

\section{Perspectives on the expertise of lay panel members}

Our research did not aim to evaluate views about panel members. However, social workers' explanations of their ideas about safeguarder appointments included reservations about the capacities of lay people, especially those with less experience, to make complex decisions such as those in permanency cases, where a family for life is sought through adoption or other permanent legal measure:

Because we are sharing our knowledge and experience and assessments with them, and they need to be able to read that and understand it, and make a competent decision. So [...] panel members [...] who are experienced, would go some way. Don't put new panel members on when you're asking about contact being terminated because of $x, y, z$. It's a big deal, and it obviously lies heavy with them, so they defer the decision by making a safeguarder appointment. (Social worker, group discussion)

I think permanency is complex [...] so by the time we're making that as a recommendation, there is a lot of evidence there, and there is a very good reason why this child cannot be returned to their parent [...] but they seem to really struggle making those decisions. It's as though they don't understand the process. (Social worker, group discussion)

Equally, some safeguarders' voiced reservations about panel members' ability to understand when it was, or was not, appropriate to appoint a safeguarder:

You usually have a biased set of information that people are being asked to form a view on [...] I blame the lack of understanding of panel members as to the importance of having a check or balance. (Safeguarder, group discussion)

I think often panel members don't really understand what safeguarders are there for, and they seem to get quite troubled with thinking of what's the safeguarder's remit, which is a word they often come out with. (Safeguarder, group discussion)

Some social workers and safeguarders felt that panel members who lacked expertise were unable to fully understand the information provided in social workers' assessments:

...we actually feel that panel members now seem less well-equipped, and I sometimes think not only 'have they read my report?', [but] 'have they actually read these papers?' (Safeguarder, group discussion) 
A lot of the issues are due to the lack of training the panel members get. They just do not [understand] the level of work or information that's in the assessments that we are providing. (Social worker, group discussion)

Social workers felt that panel members underestimated the extent to which their assessments and recommendations incorporated expertise from a range of other professionals such as health professionals, teachers, and others; although, this could equally indicate that social workers had not effectively conveyed the nature and extent of multi-agency contributions.

These participants also reported that some panel members seemed to find it difficult to deal with emotional pressure applied by, or on behalf of, parents:

And they get totally drawn in by the parents and by, like, the lawyers, and things like that. (Social worker, group discussion)

Equally, they suggested that some panel members lacked the skills or confidence to handle conflict, and so, might rely on a safeguarder's involvement to help achieve resolution:

They [the panel members] were intimidated by the parents, rather than making the decision, because they were frightened it was all gonnae kick-off in the panel. (Social worker, group discussion)

Safeguarders and social workers often talked about panel members requiring more training: I think they must have (better training)... their hearts are in the right place, they're trying to help the system, it's the training that they're getting, there is some flaw. (Safeguarder, group discussion)

Their lack of training on the whole subject of attachment and the impact this has on a traumatised child to make sense of their world, is abysmal, causing further delay throughout the whole process, as these laymen are being asked to make substantive decisions that affect these children's lives on matters of which the panel clearly have very little knowledge or understanding about. (Social worker, questionnaire)

In contrast, some panel members believed they possessed the necessary knowledge and skills to reach correct decisions about appointing a safeguarder:

I am always so amazed at how right that hearing was to appoint the safeguarder at that particular stage, and how good the outcome seems to be afterwards, you know? 
[...] you look back and the right decision is made [...] So somewhere along the line, our training, our understanding and our picking up of when to do this, seems to be, generally, quite good.(Panel member, group discussion)

Certain panel members, though, acknowledged that they sometimes lacked the confidence to make a decision without recourse to the perceived expert opinions of safeguarders:

I suppose I worry that we can abdicate responsibility on occasion when we shouldn't or needn't. (Panel member, questionnaire)

I think that in the very challenging circumstances faced by so many of our hearings just now, it can be easy to default to a Safeguarder iffaced with aggressive or belligerent parents. (Panel member, questionnaire)

Panel members' perceived lack of confidence was reported to be a particular issue in relation to permanence cases. Many social workers, and indeed some safeguarders, thought that once a plan for permanence was made, all cases should go straight to a Sheriff court rather than a Children's Hearing. They asserted that the training and court experience of Sheriffs meant that they would be better able to handle the process dispassionately:

Taking the emotion out of that [a recommendation for permanent removal of a child], 'What are the facts in this case?', 'Why is that the recommendation?', and 'Is that in the best interests of the child?'. I think taking that out of the panel, probably would be in the child's best interests. (Social worker, group discussion)

Another rationale was that the formality and authority of courts would reduce delays in decision making for permanence:

I mean, if you go to a Children's Hearing and the parents don't turn up, it will generally be deferred to allow the parents to come. If they don't turn up at court, the Sherriff doesnae defer it. D'you know, it goes ahead. (Social worker, group discussion)

Another argument put forward to support this idea was that greater frequency of legal representation had increased the confrontational nature of hearings, and the probability of appeals to the Sheriff, so that it made sense to go direct to the courts and avoid a double process.

I certainly don't mind ever being questioned, in terms of my view. I'm quite happy to account. But let's get it into a legal process, you know. Do it in a court of law. (Social 
worker, focus group)

\section{Values and expertise}

Most comments about perceived expertise focused on knowledge and skills, but participants also drew attention to differences in values. Often when discussions turned to legally trained safeguarders and legal representatives, issues emerged about the appropriate set of values for work in children's hearings. As aforementioned, social workers and some panel members had reservations about legally-trained safeguarders. Concerns focused on their perceived lack of knowledge about child development and attachment, and their experience of working with children. Some participants also raised ethical concerns questioning whether legally trained safeguarders could be convincingly neutral, as their usual role required them to advocate strongly for one side. The following quotation refers to the same individual on one occasion acting as a legal representative for a parent, and in another case, performing the safeguarder role:

...one of our safeguarders [...] he's also a legal rep, so you can have him in a hearing one week, not working, in my opinion, in the best interests of the child. [...] he's sitting there for mum and dad, banging on about their legal rights and the next week, an almost identical case, and he is saying that under no circumstances should these children [be removed] and I find that very difficult, very difficult. (Panel member, group discussion)

Our study did not aim to collect views about the involvement of legal professionals in the hearings; however, this emerged from discussions. Panel members and social workers often expressed concerns about the increasingly confrontational nature of hearings, which they attributed at least in part to the increased use of legal representation by parents:

But our hearings are becoming so challenging [...] and so legalistic (with more lawyers then ever attending, and not quietly!) that it is becoming very hard to be a panel member! (Panel member, questionnaire)

Members of all three groups of respondents made statements suggesting that combative legal professionals who opposed social work plans on behalf of parents, were unduly influencing panel members:

Perhaps a noisy and aggressive parent or the presence of a lawyer can influence the panel to appoint a safeguarder to re-visit previous decisions, to placate the unhappy 
parent/other person. (Safeguarder, questionnaire)

I think more and more [...] families are coming along to hearings with solicitors now, as well. And a lot of the panel members are maybe intimidated and don't want to make the decision. The lawyers are supposed to be there to support their client, but they're actually having a full-blown conversation and discussion, taking part, and guiding, in the hearing. (Social worker, group discussion)

The adversarial attitude allegedly adopted by some lawyers was widely seen as at odds with the broadly consensual aims of hearings:

A solicitor who is being very abrasive can actually make a huge difference to a hearing. So, you know, it makes me wonder, sometimes, whether or not solicitors are the right people to be safeguarders. (Panel member, interview)

An English study in relation to care proceedings revealed that lawyers saw it as part of their role to question local authority recommendations, but were also prepared to challenge parents and 'favoured agreed solutions over ones that were imposed' (Masson, 2012, p. 205)

\section{The impact of perceptions of expertise on decision making}

Social workers doubted that some safeguarders' reports presented new evidence to Children's Hearings. Many thought that safeguarders often reformulated the same information they themselves had already made available, and added little to social work assessments. They concluded that the safeguarder appointment simply delayed decision-making, with little or no benefit:

So we've got that far, and when we've come so far down the line in terms of permanency, why delay it again by putting in a safeguarder? At that point, let it go through due process. That's the family's opportunity, apart from the panel, to have their view, and be represented legally in an open forum. (Social worker, group discussion)

Many panel members also acknowledged that the additional expert assessments and reports from a safeguarder were not likely to change the eventual decision. Even so, they felt that the second opinion provided by the safeguarder was useful, and allowed them, and the parents, to be more confident in, or committed to, the decision:

The majority of times they're going to come back with the same decision and yet, I 
agree, I think that is a good point. I don't think it's a waste of time. I don't think that there wasn't any remit for the safeguarder; I think it just removes the disagreement and confusion that it can cause panel members because, unfortunately, you can maybe sometimes have a social worker who's slightly overzealous with things as well. (Panel member, group discussion)

Several panel members and safeguarders commented that while a safeguarder report might not add much in terms of new information, by reinforcing social worker recommendations it would help parents and their legal representatives to accept a decision:

An independent report is useful [...] a good indicator to the relevant persons (and their legal representatives/solicitors if involved) that the panel have thoroughly examined the case before making a significant decision. (Panel member, questionnaire)

They felt this could be especially helpful when the safeguarder acknowledged the merits of the parents' position:

And they might, the safeguarder might come back and say, 'well, I don't quite agree with this but, overall, I still agree with the social worker's decision.' So it gives something back to parents, as well, because we're not all right all the time. (Panel member, group discussion)

Panel members suggested that this might in turn reduce the likelihood of an appeal, so that the additional time taken might save more time in the end.

\section{Discussion}

Decisions about permanent care arrangements for a child or young person are potentially life changing, not only for the child, but also for their family. The option that will best promote the child's welfare is rarely clear-cut and is frequently contested. Most participants in this study recognised that Scottish Children's Hearings, like any youth or family court system, need access to a mix of competencies, including expertise in children's needs and development and expertise in the law. Some participants also recognised and valued the benefits of lay input from citizens.

The focus of our study was on safeguarders, but in considering their role participants reflected on the expertise of a wide range of actors within the hearing. Most participants acknowledged safeguarders' 
contributions, constructing their perception of safeguarders around and in reference to their views of other roles and features of the system including what counts (and should count) as appropriate expertise, knowledge, skills, and values.

These participants clearly recognised that exercise of expertise was a complex and sometimes constrained activity that was (or should be) shaped by the context. For instance, the objectivity of a social worker's assessment of a child's best interest was sometimes queried as potentially affected by management decisions, departmental priorities or budgets, while a lawyer's adversarial courtroom skills were sometimes reported to be misapplied within the 'less formal' setting of hearings.

It was agreed that time and skills were needed to help identify and convey a child's wishes, but disagreement occurred about who was best placed to carry out this task. Many respondents, even those with misgivings, saw safeguarders as having advantages in this work, being independent of both the bureaucratic constraints of local authority social workers, and the participation of lawyers.

Panel members constructed an image of safeguarders as an independent expert, and contrasted this with their view of local authority social workers, whose expertise or neutrality they sometimes questioned, despite presumably, being aware of the professional qualifications that social workers hold. From this perspective, they did not see social workers as independent experts, but as operatives of the state (Doughty, 2009; Duquette \& Darwall, 2012; Lockyer \& Stone, 1998). Their concern and consideration of this issue reflects the point made by Reid and Gillan (2007), that there are inevitably moral or evaluative components alongside rationality in decision-making about children. Despite this, recent research has confirmed that in most cases hearings decisions agree with social workers' recommendations (Henderson \& Hanson, 2012).

Concerns about how social workers' expertise is portrayed, or low levels of confidence in the profession have been reported elsewhere. For example, in a study considering decision-making in care proceedings in England and Wales, Beckett et al. (2007) note that many social workers felt that the courts disregarded their knowledge and expertise and gave too much weight to the views of expert witnesses and children's guardians. Similarly, Munby (2013a, 2013b) writing as head of the Family Division in London, noted that lack of confidence in social workers has led courts to overuse other experts. He suggested that it is therefore desirable to 're-position social workers as trusted professionals' (Munby, 2013c, p. 3). Unsurprisingly, social workers in this study often regretted hearings' appointments of safeguarders. They were not only concerned that it indicated a general lack of trust in their expertise, but that this introduced delays to decision-making. They asserted that their assessments often included input from other professionals, such as teachers, doctors, and nurses, but it seems this wider base for 
recommendations was not always clear to decision-makers. Social workers' complaints about their compromised status and the deference shown to the views of safeguarders should not be seen simplistically as professional jealousy (cf. Beckett, McKeigue, \&Taylor (2007).

Such concerns raise important issues about the meaning and limits of expertise in child care proceedings, in particular, how decision-makers' commissioning and use of expertise promotes children's best interests. This study and others suggest that a greater number of opinions may sometimes result in further conflict and delays, which may not necessarily result in better decisions for children. In our study, concerns were expressed that safeguarders may sometimes duplicate what is already known or knowable. In response to similar concerns in England and Wales, the Child and Family Act 2014 constrained the circumstances in which expert witnesses could be appointed in public law proceedings. Courts must consider, among other factors, whether information could be obtained from those already involved in the proceedings.

Our findings have also highlighted that the safeguarder's training, experience, and qualification is often not clear to other actors in the hearing. This concerned social workers who felt it necessary to understand the safeguarder's expertise in order to weigh their recommendations; it did not appear to trouble panel members who were clearly confident that safeguarders were experts. Beckett et al. (2007) argued with regards care proceedings in England and Wales, 'irrational beliefs' may emerge amongst decisionmakers on the infallibility of some or other participant, as this helps them to better cope with the difficulties they face in making a decision.

Lay panel members' knowledge and skills were also questioned in our study. Some of our participants stated that emotional disputes and fervent advocacy make it hard for laypersons to manage the hearing or make dispassionate decisions. Panel members' appointment of a safeguarder may often be an attempt to address these issues by demonstrating that the process is objective or deferring the decision to a point when parents and solicitors are thought less likely to dispute it. This should not be viewed simplistically as an attempt to avoid uncomfortable conflict, panel members felt that by securing greater consensus within the hearing, later delays to permanency for the child might be avoided. Removing the lay contribution to the process would not only take away the 'expertise' of common sense, but would also leave the whole process in the hands of state-funded court and service systems, detached from the local citizens who are affected by breaches of public law in their community (Reid and Gillan, 2007).

Expertise is not only grounded in knowledge and skills, but in values (Carnochan et al., 2008). In relation to private law cases, Doughty (2009) has argued that lawyers and judges have a legal ethic to practise adversarially, based on individual rights and justice, whilst social workers have an ethic of care that 
emphasises conciliation and equal treatment, at least in private law cases. In this study, participants portrayed different actors as having different values and priorities, as when a child's or parent's right to family life was balanced against a child's best interests. The Scottish Children's Hearings System has been largely based on a consensual approach, but in the eyes of some of our respondents and external commentators, has come under increasing pressure to move towards a legal ethic (Mooney \& Lockyer, 2012). These concerns seem most strong in relation to cases involving complex abuse and permanence. Many of our participants were strongly committed to the ethos and values of the hearings system and were concerned about the involvement of individuals driven by other ethical codes. The continued contribution of lay members and hearing-appointed safeguarders may be particularly helpful where ethical systems appear to be in tension.

\section{Conclusions}

In public law decisions, such as those made in children's hearings, decision-makers must balance diverse considerations that often seem to be tension with each other; for example, children's best interests and children's wishes; legal expertise, child development expertise and lay expertise; parents' rights and children's rights; and, decision quality and decision timeliness (Buss \& Maclean, 2011; Liljegren et al., 2014). Critically, we have shown that decision-making where these tensions prevail is likely to be affected by various actors' perceptions of each other's expertise and the context in which professionals are able to operate their expertise. These perceptions are themselves contested, potentially resulting in friction, the deployment of resource, and addition of further time that sometimes appears to have little impact on the type of decisions that are made. This raises the interesting question of what constitutes 'quality' in decision-making and whether this may include other features beyond arriving at a 'right' answer.

It was not the intention of this article to reach a definitive conclusion about the best blend of expertise to reconcile these considerations. Rather we have examined the arguments surrounding legal expertise, social work expertise, and lay expertise in respect of decision-making for permanence, and illustrated how these ideas are inevitably linked to the prevailing systems in the jurisdiction.

Our study showed that alongside the particular combinations of professional knowledge and skills and lay input, it is also important to understand how those involved, view, and portray the expertise of decision-makers, information providers, and representatives. Of particular importance are decisionmakers' beliefs about the salience of legal and child development knowledge, skills in communication with children, and the nature and quality of written and verbal presentations. These perspectives have 
consequences. When the expertise of social workers is doubted, then additional time may be taken up on obtaining further inputs. In our study, opinion indicated that this resulted in a better decision only some of the time. Social workers saw some resulting delays as detrimental to children, though some panel members argued that obtaining additional input reduced the potential for delays arising from later appeals.

Finally, we would suggest that a lack of mutual understanding and trust among decision-makers and professionals is likely to be detrimental to wider confidence in any system. The development of greater clarity and respect for each key role is urgently needed. Opportunities for inter-disciplinary training, building trust in each other, and improved understanding of each other's qualifications and roles may be a useful place to start.

\section{Acknowledgements}

This study was undertaken within a larger programme of work funded by Scottish Government that aims to improve permanence processes for looked after children. Many partner groups were involved in the study and in taking findings forward, we thank all participants and the organisations and individuals who helped us to gain access to those participants.

\section{References}

Abbott, P., \& Wallace, C. (Eds.). (1990). The sociology of the caring professions. London: Falmer. ALRC. (1998). Seen and heard: priority for children in the legal process. Retrieved from Canberra: Beckett, C., McKeighe, B., \& Taylor, H. (2007). Coming to conclusions: social workers' perceptions of the decision-making process in care proceedings. Child and Family Social Work, 12(1), 54-63.

Bilson, A., \& White, S. (2005). Representing children's views and best interests in court: an international comparison. Child Abuse Review, 14(4), 220-239. doi:10.1002/car.902

Borowoski, A., \& Sheehan, R. (2012). Magistrates's perspectives on the criminal division of the children's court of Victoria. Australian Social Work, 66(3), 1-16.

Braun, V., \& Clarke, V. (2006). Using Thematic Analysis in Psychology. Qualitative Research and Psychology, 3, 77-101.

Buss, E., \& Maclean, M. (2011). Law and child development in the UK and the US. Journal of Children's Services, 6(4), 236-247. doi:doi:10.1108/17466661111190938

Capita. (2004). Review of the guardian ad litem service. Retrieved from Dublin:

Carnochan, S., Taylor, S., Abranson-Madden, A., Meekyung, H., Rashid, S., Maney, J., . . Austin, M. J. (2008). Child Welfare and the Courts: an exploratory study of the relationship between two complext systems. Journal of Public Child Welfare, 1(1), 117-136.

Children 1st. (2014). Becoming a safeguarder. Retrieved from http://www.children1st.org.uk/what-wedo/our-services/search-our-services/safeguarders-panel/becoming-a-safeguarder/\#competencies

Cover, M. (2012). O guardian, where art thou? Seen and Heard, 22(2), 37-45.

Dickens, J. (2010). Social Work and Social Policy. London: Routledge.

Doughty, J. (2009). Identity crisis in the family courts? Different approaches in England and Wales and 
Australia. Journal of Social Welfare and Family Law, 31(3), 231-243.

Duquette, D. N. (1994). Scottish Children's Hearings and representation for the child. In S. Asquith \& M. Hill (Eds.), Justice for Children. Dordrecht: Martinus Nijhoff.

Duquette, D. N. (2001). Legal representation for children in protection proceedings: Two distinctive lawyer roles are required. Family Law Quarterly, 34(3), 441-466.

Duquette, D. N. (2007). Children's Justice: a view from America. In M. Hill, A. Lockyer, \& F. Stone (Eds.), Youth justice and child protection. London: Jessica Kingsley.

Duquette, D. N., \& Darwall, J. (2012). Child Representation in America: Progress Report from the National Quality Improvement Center. Family Law Quarterly, 46(1), 87-137. Retrieved from http://ezproxy.lib.ed.ac.uk/login?url=https://search.ebscohost.com/login.aspx?direct=true \&db=ap $\underline{\mathrm{h} \& \mathrm{AN}=89969295 \& \text { site }=\text { eds-live }}$

Eraut, M. (1998). Concepts of competence. Journal of Interprofessional Care, 12(2), 127-139. doi:doi:10.3109/13561829809014100

Etzioni, A. (1969). The semi-professions and their organization: teachers, nurses, social workers. London: Collier-Macmillan.

Gadda, A. M., Hill, M., Young, E., \& Welch, V. (2015). The appointment of safeguarders in the Children's Hearings System. Retrieved from Glasgow:

Gilbert, T., \& Power, J. L. (2010). Power and social work in the Univert Kingdom: A foucauldian excusion. Journal of Social Work, 10(1), 3-22. doi:10.1177/0733464809335596

Glynn, G. F. (2007). The Child Abuse Prevention and Treatment Act - promoting the unauthorized practice of law. Journal of Law and Family Studies, 9(1), 53-63.

Gupta, A., \& Lloyd-Jones, E. (2010). The representation of children and their parents in public law proceedings since the Children Act 1989: high hopes and lost opportunities? Journal of Children's Services, 5(2), 64-72. doi:doi:10.5042/jcs.2010.0303

Hallett, C., Murray, C., Jamieson, J., \& Veitch, W. (1998). The evaluation of children's hearings in Scotland: volume 1; deciding in children's interests. Retrieved from Edinburgh:

Henderson, G., \& Hanson, L. (2012). Children on Supervision Requirements for Five or More Years Decisions and Outcomes. Retrieved from Stirling:

Hetherington, R., Baistow, K., Katz, I., Mesie, J., \& Trowell, J. (2001). The welfare of children with mentally ill parents: learning from inter-country comparisons. London: Wiley.

Hill, M., Lockyer, A., Morton, P., Batchelor, S., \& Scott, J. (2003). Safeguarding children's interests in welfare proceedings: the Scottish experience. Journal of Social Welfare and Family Law, 25(1), $1-21$.

Hill, M., \& Taylor, R. (2012). The Kilbrandon Lectures: Reflections on care and justice for children in Scotland. Retrieved from Edinburgh:

Kearney, B. (2000). Children's Hearings and the Sheriff Court. Edinburgh: Butterworths Law.

Kirton, D. (2009). Child Social Work Policy and Practice. London: Sage.

Korpinen, J., \& Poso, T. (2007). Approaching youth crime through welfare and punishment: the Finish perspective. In M. Hill, A. Lockyer, \& F. H. Stone (Eds.), Youth Justice and Child Protection. London: Jessica Kingsley.

Lehrmann, D. H. (2010). Advancing children's rights to be heard and protected: The model representation of children in abuse, neglect, and custody proceedings act. Behavioral Sciences and the Law, 28(4), 463-479. doi:10.1002/bsl.943

Liljegren, A., Höjer, S., \& Forkby, T. (2014). Laypersons, professions, and governance in the welfare state: The Swedish child protection system. Journal of Professions and Organization, 1(2), 161175. doi:10.1093/jpo/jou005

Lockyer, A. (1992). Citizenship service and children's panel membership. Retrieved from Edinburgh:

Lockyer, A. (1994). Commentary on Donald Duquette's Proposal. In S. Asquith \& M. Hill (Eds.), Justice for Children. Dordrecht: Martinus Nijhoff.

Lockyer, A., \& Stone, F. (Eds.). (1998). Juvenile Justice in Scotland. Edinburgh: T\&T Clark.

Mantle, G., Williams, I., Leslie, J., Parsons, S., \& Shaffer, R. (2008). Beyond assessment: social work 
intervention in family court enquiries. British Journal of Social Work, 38(3), 431-443.

doi:10.1093/bjsw/bcl346

Masson, J. (2012). "I think I do have strategies": Lawyers' approaches to parent engagement in care proceedings. Child and Family Social Work, 17, 202-211.

Mooney, A., \& Lockyer, A. (2012). Children's representation. In M. Hill, G. Head, A. Lockyer, B. Reid, \& R. Taylor (Eds.), Children's Services: Working Together. London and New York: Routledge.

Munby, J. (2013a). View from the President's chamber (2). Retrieved from London:

Munby, J. (2013b). View from the President's chambers (1). Retrieved from London:

Munby, J. (2013c). View from the President's Chambers (3). London: Family Division.

Noordegraaf, M. (2007). From "Pure" to "Hybrid" Professionalism: Present-Day Professionalism in Ambiguous Public Domains. Administration \& Society, 39(6), 761-785. doi:10.1177/0095399707304434

Norrie, K. (2009). Family Law. Dundee: Dundee University Press.

Norrie, K. (2013). Children's Hearings in Scotland (3rd ed.). Edinburgh: W. Green.

Ofsted. (2014). Children and Family Court Advisory and Support Service (Cafcass): Inspection of Cafcass as a national organisation. Retrieved from Manchester:

Parry, N., \& Parry, J. (1979). Social work, professionalism and the state. In N. Parry, M. Rustin, \& C. Satyamurti (Eds.), Social Work, Welfare and the State. London: Edward Arnold.

Parton, N. (1996). Introduction: Social theory, social change and social work. In N. Parton (Ed.), Social Theory, Social Change and Social Work. London and New York: Routledge.

Prescott, D. E. (2013). Social workers as "experts" in the family court system: Is evidence-based practice a missing link or host-created knowledge? Journal of Evidence-Based Social Work, 10(5), 466481. doi:10.1080/15433714.2012.759844

Reid, B., \& Gillan, I. (2007). The place of lay participation in decision-making. In M. Hill, A. Lockyer, \& F. Stone (Eds.), Youth Justice and Child Protection. London: Jessica Kingsley.

Russell, P. H. (2012). Judicial Recruitment, Training and Careers The Oxford Handbook of Empirical Legal Research.

Ryrstedt, E., \& Masttson, T. (2008). Children's rights to representation: A comparison between Swden and England. International Journal of Law, Policy and the Family,, 22(1), 135-147.

Ryrstedt, E., \& Mattsson, T. (2008). Children's rights to representation: A comparison between Sweden and England. International Journal of Law, Policy and the Family, 22(1), 135-147. doi:10.1093/lawfam/ebm001

Scotland, R. b. t. C. A. b. t. S. o. S. f. (1964). The Kilbrandon Report: Children and Young Persons Scotland. Retrieved from Edinburgh:

SCRA. (2015). Statistical Analysis 2014-15. Stirling: Scottish Children's Reporter Administration. http://www.scra.gov.uk/wp-content/uploads/2016/03/SCRA-Statistical-Analysis-2014-15.pdf. Accessed April 2016.

Stötzel, M., \& Fegert, J. M. (2006). The Representation of the Legal Interests of Children and Adolescents in Germany: A Study of the Children's Guardian from a Child's Perspective. International Journal of Law, Policy and the Family, 20(2), 201-224. doi:10.1093/lawfam/ebi023

Taylor, R., Hill, M., \& Milligan, I. (2015). Children's Hearings, Residential Child Care and Professional Education Journal of Scottish Residential Child Care.

Thomson, L., McArthur, M., \& Camilleri, P. (2015). Is it 'fair'? Representation of children young people and parents in an adversarial court system. Child \& Family Social Work. doi:10.1111/cfs.12226

Ward, T. (2012). Expert evidence, judicial reasoning, and the family courts information pilot. Journal of Law and Society, 39(4), 515-540. doi:10.1111/j.1467-6478.2012.00598.x 